University for Business and Technology in Kosovo

UBT Knowledge Center

Oct 27th, 1:30 PM - 3:00 PM

\title{
City center, underground infrastructure, the application of space syntax
}

Arsim Mureli

University for Business and Technology, arsim.murseli@ubt-uni.net

Follow this and additional works at: https://knowledgecenter.ubt-uni.net/conference

Part of the Architecture Commons

\section{Recommended Citation}

Mureli, Arsim, "City center, underground infrastructure, the application of space syntax" (2018). UBT International Conference. 5.

https://knowledgecenter.ubt-uni.net/conference/2018/all-events/5

This Event is brought to you for free and open access by the Publication and Journals at UBT Knowledge Center. It has been accepted for inclusion in UBT International Conference by an authorized administrator of UBT Knowledge Center. For more information, please contact knowledge.center@ubt-uni.net. 
Book of Proceedings

International Conference on Architecture and Spatial Planning

\title{
City \& city center, the application of space syntax
}

\author{
Arsim Murseli ${ }^{1}$ \\ UBT - Higher Education Institution, Lagjja Kalabria, 10000 p.n., \\ Prishtine KOSOVA arsim.murseli@ubt-uni.net
}

\begin{abstract}
The city, the urban space is in the process of continuous urban change, a process that is encouraged by complex structures and systems, a process that also needs to be addressed, discussed to be addressed and redirected. The topic of my study is the city center as a central and representative area of each city with, the application of spatial syntax analysis in urban research and planning.
\end{abstract}

Sustainable development of a solution that can be characterized by a process in which the quality of life is developed in such a way that social and economic life is not a threat to the survival of environmental elements and ensure the improvement of their continuity.

An appropriate downtown infrastructure solution that would provide a resilient center that is able to change. It is an attempt to multidisciplinary thinking as an urban phenomenon in all dimensions at once: social, ecological, economic and cultural. The process, which will be a continuation, which defines a number of steps in transforming the city for the coming decades.

Keywords: space syntax 1, city center2. infrastructure3, elasticity4 


\section{FORWARD}

My research topic is the city of Ferizaj, which is located in the youngest state in the Balkans, called Kosovo. This city was built thanks to the railway, which has given importance and weight to this city which has been developed on both sides of the railway. The railway has a regional and international importance, why not say intercontinental. Railway as such, with the importance and role it has in the overall global network, the city of Ferizaj will not deal with its treatment, but will try to maintain the position of the railway in the integration of sustainable solutions of the city, once creating an unimpeded mobility of the city and the railway.

Such a solution means organizing the expansion and functioning of the city. A city is functional if it solves mobility or otherwise what is called traffic, here is the traffic of automobiles, railways and pedestrians, or as it is called the route from point A to point B. A solution that will enable the creation of the pedestrian oasis, e which will create functional connections with other urban areas of the city. It should not be forgotten that in the center, sidewalks, pedestrian paths, streets and squares of the city we are all guests, it does not matter if we live in that city or are from another city, this also gives a reason plus in the treatment and approach of the organization of the city center as well as all elements or public spaces.

The elements of the city are partially inseparable where each part affects the other and are connected so that they function as a whole. Every action on one element is important how it will affect other parts or other elements, because it can very easily be transformed in a nonfunctional space. so the city presents a problem, while the main problem is how to understand this action that each part affects each other. Under a complexity however there is a simple basis, city life ultimately constitutes the individual action of the people living in it from working, meeting, trading and relaxing, each of us is partly responsible for all these actions and each of us has our own unique relationship with the city, how we see it or not, how we experience it or not, through our actions we build life in the city. So what are our actions and how are they defined. JJ Gibson thinks that our actions are the result of the combinations of opportunities offered to us by the environment in which we live. we can measure a map an asset in a form of a potential movement and action in the environment. we can make it possible for lines to come from one action to another, from one place to another. these lines are not merely a representation of our space, but a part of our being. they set out how we can act in the environment and present a summary of the potentials of life in that environment.

\section{But what do we think of a sustainable solution}

The main idea in the concept is the use of resources that respect the interests of future generations, and at the same time, taking into account the social, economic and environmental aspects.

Understanding sustainability and sustainable development always raises debates in professional, scientific and political circles, which are open every time. Which focus on selfdetermination and interpretation in everyday life. 
No one knows the future, but we can give direction, what we have today is the legacy of past generations, as a result of collective thinking. The life cycle, the degree of collective thinking, the factors that affect the existence of the spending society, often provide immediate solutions, unsustainable emergency solutions, unfortunately this is also expressed in other areas.

Collective thinking is the compatibility of public circles with the choice of scenarios that will be part of public discussions. Scenarios are discoveries of the future, but they are not predictions, they take on strength when combined with predictive models, analysis and studies, but can also be warning signals that allow decision makers to anticipate unexpected changes.

There is a permanent gap between theory and practice. It is always a problem to find the bridge between them. The theory, no matter how well described, explained and logical, still remains abstract or multidimensional and that it depends on the level of intellect of a society, the professional training of experts in the field, the level of economic, technological and social development, in a word the evolutionary scale of a society. How much she is able to accept and implement the changes.

But change in a city that has a legacy of spontaneous development is a challenge in itself. The human-environment relationship is a correlation, just as we act in the environment, so the environment affects us. A man who lives a long time in an environment, he very easily embodies it and reflects that environment, his intellect does not exceed the boundaries of that environment (Kevin Lynch-The image of the city).

In the Preface to my scientific work from 2018 Urban blocks, geometric methods, application of space syntax

Where I have mentioned the reasons for the failure and time delay of the urban and spatial development process which are:

- Necessary preliminary experience, which is lacking, the city did not have any regulatory plan or development plans, much less general urban plan, except for some parts which were worked on 40 years ago, and as a result of this flow

- Spontaneous constructions, which have formed a network of elongated roads and alleys with inadequate profile with an extension and positioning that creates a non-functional network.

- Professional training is not proven to be at the right level for the preparation of documentation and approach to this problem. to this should be added the preparation for presentation at public gatherings for discussions with citizens, as a result of this:

- Public discussions are very noisy and long without results, while;

the construction process continues with the rules that only further complicate the situation in the city. 
As a result, in 2008 the competition for the solution of the mobility center was announced, which was not successful. A decade later, the Municipal Assembly of Ferizaj in 2017 announced the competition for the design of the infrastructure project, which will enable the movement of vehicles and citizens from one part to another without being hindered by the movement of rail traffic, where I participated for solutions functional and urban of these segments, projects that are now in the process of their completion.

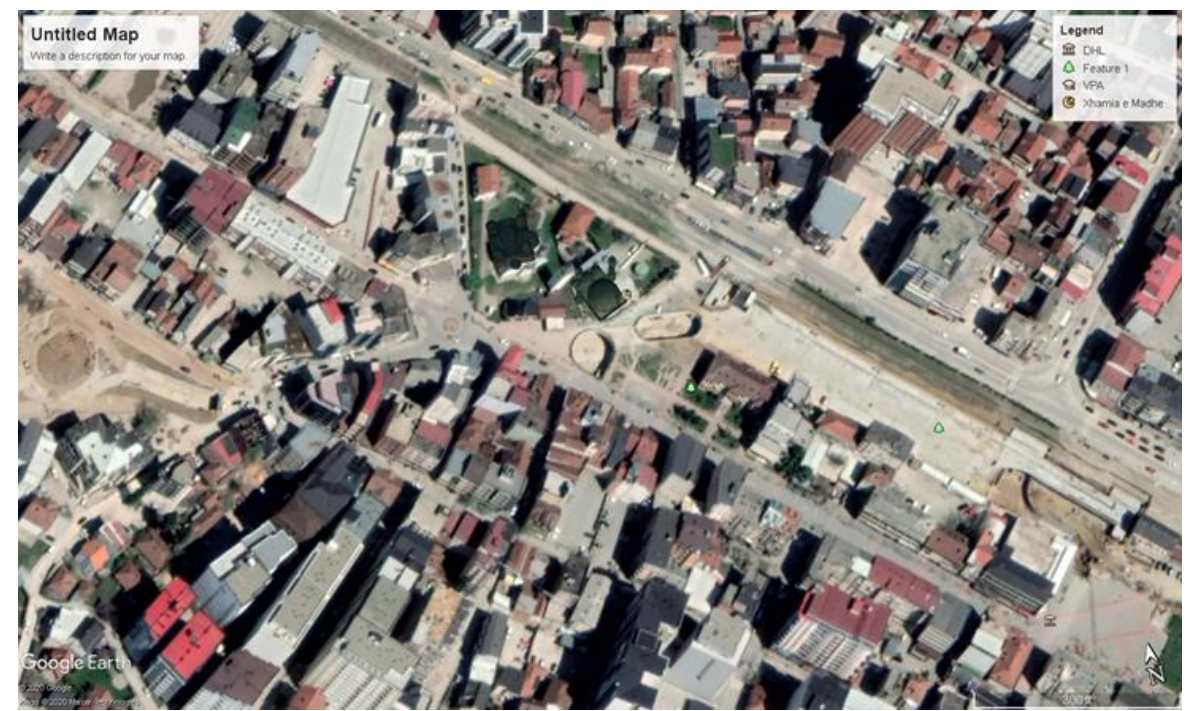

Fig.1 Rail station and center in process
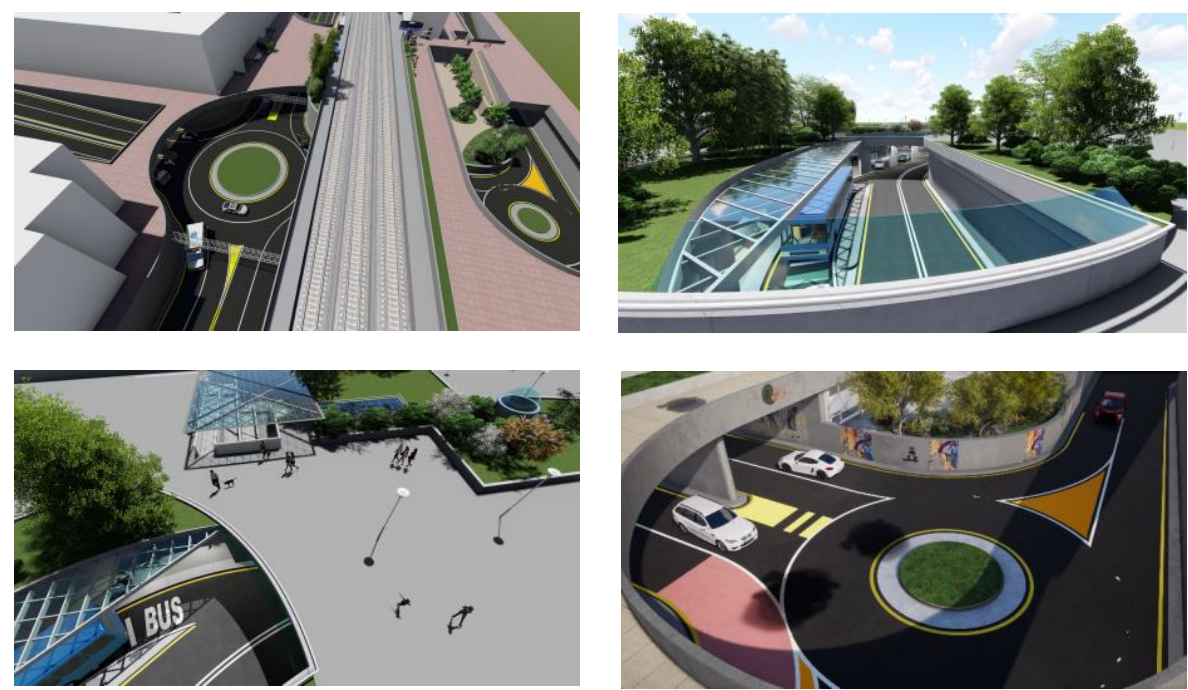
The structure shown in Fig.1 is the center which includes the regulation of the space of the railway station, the underpass of pedestrians with number of premises, as well as that of vehicles, in this segment is foreseen the public parking with a capacity of 200 parking lots, as well as in the level of square premises in front of them. The whole structure is partially covered, forming a new part of the city square, which connects with the old city square, forming a larger and richer general space, as well as an urban landscape where even surfaces are not missing. of greenery. This segment and this solution enables the operation of these three modes of unobstructed mobility in a relatively small space which offers comfort in the use of these spaces.

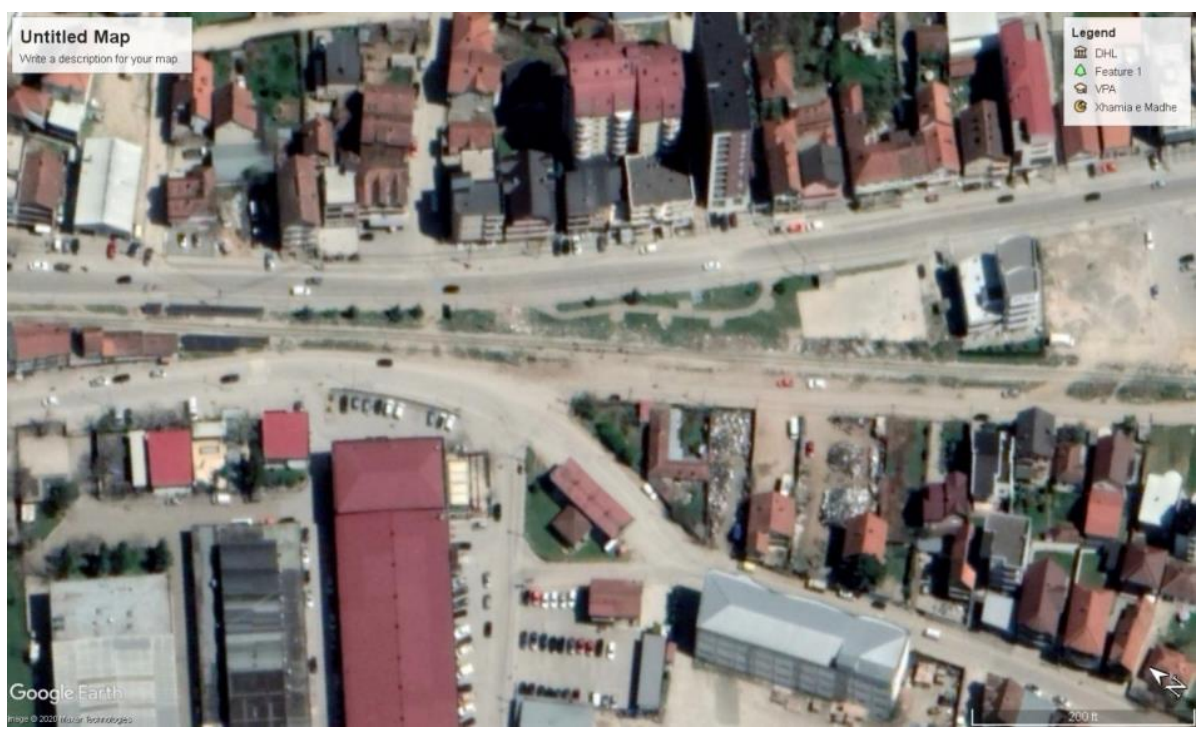

Fig. 2 trade str.
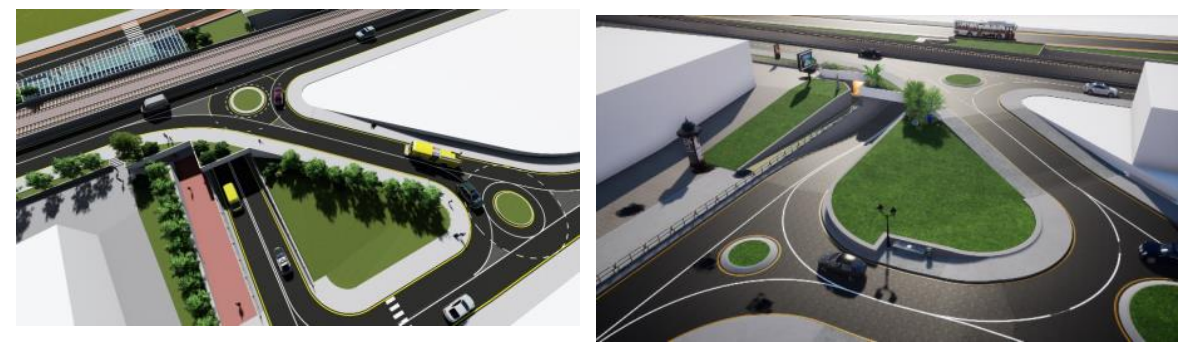

In fig. 2 is the solution of the road segment that forms a new road which represents the road which connects the city streets with the trade street respectively with the central market of the city. This structure helps the products from the suburbs as well as from other cities to reach the market more easily and quickly as well as to leave the market without interfering in other parts of the city. Which has its level under the railway, even in this solution the three modes of mobility are separated and their functioning is unimpeded or interfered with each other. 


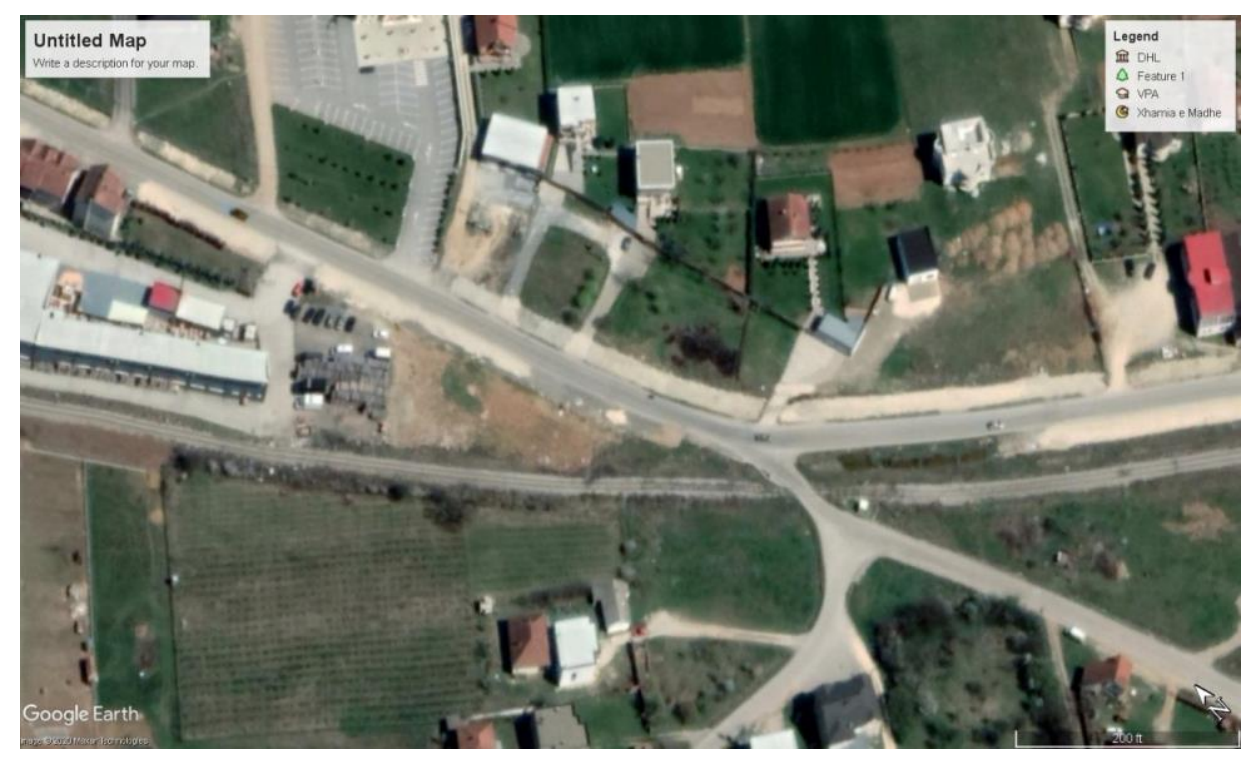

Fig.3
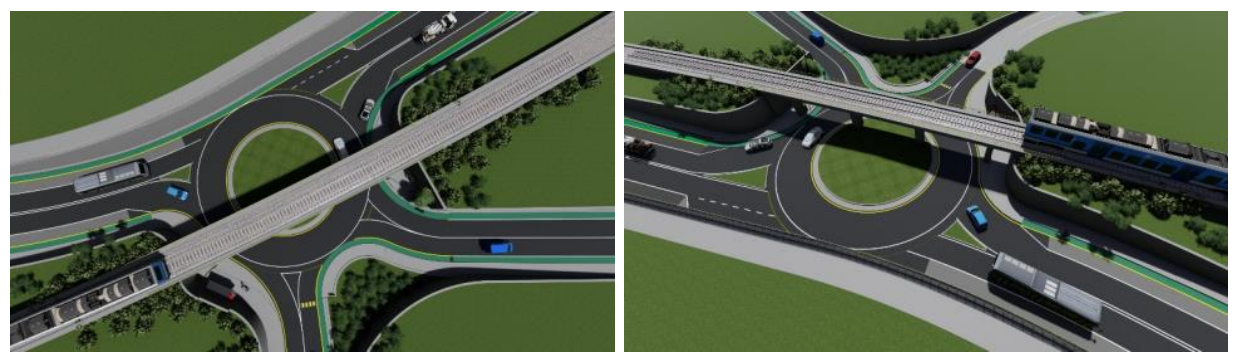

Fig.3 Represents the road segment that connects the peripheral roads of the two villages with the road segment that represents the connection of these villages with the city. This segment has so far been developed on railways, which can be seen in fig. 3 taken from google map. This segment is now completed in November 2019, and shortens the road and transforms the villages on the outskirts of the city, enables economic development and has a maximum security of mobility. 


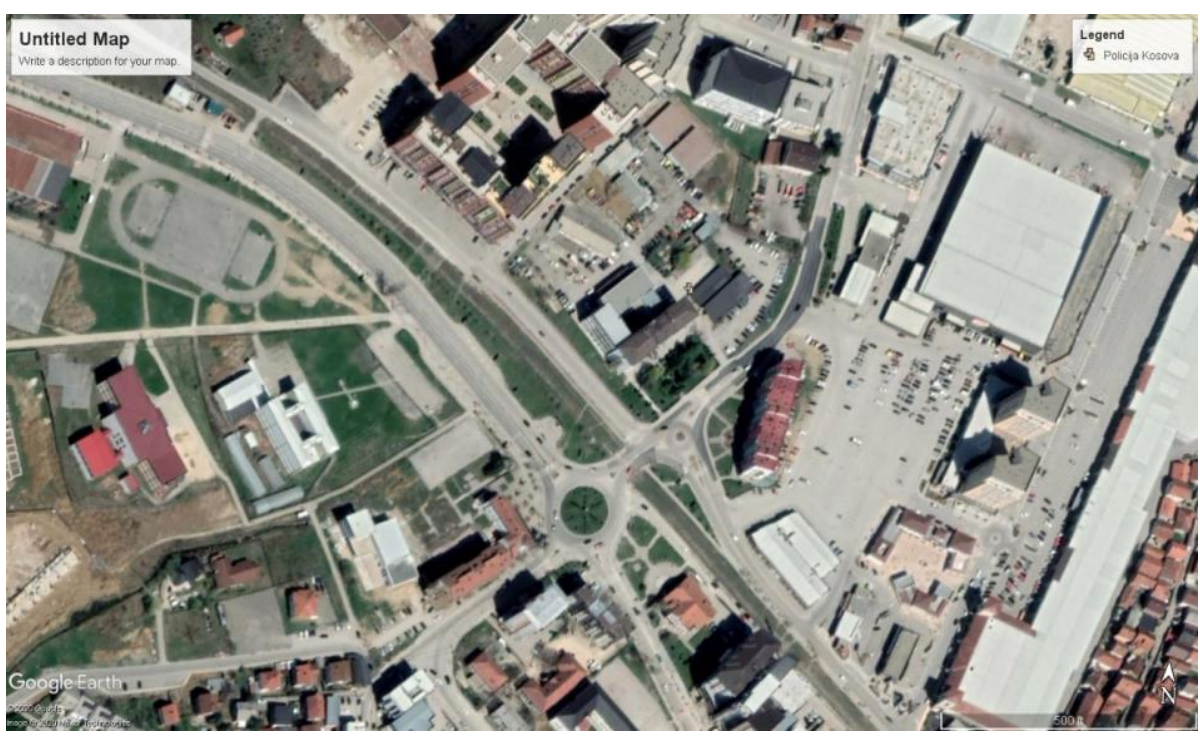

Fig.4
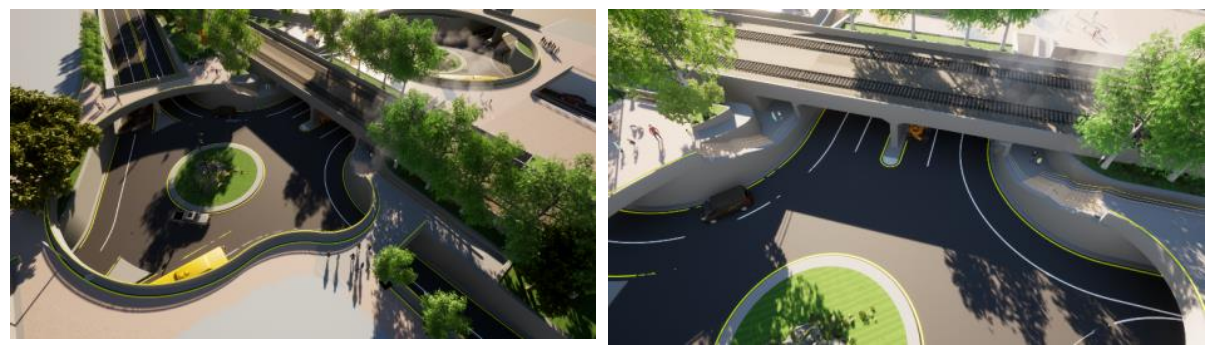

Fig. 4 shows the segment which divides the center area with the sports and recreation area. This is a project that construction should start in 2021. 
These axes or engineering and urban structures will be essential elements in the city, which will affect other urban areas. With their position in the center of the city, they provide connectivity, ie the unification of the city to form it into a functional whole, sometimes the presence of these structures is dominant as visual elements of space. The role of these axes or segments, which will be realized, will have an impact not only on the functionalization, ie the mobility of all forms, but will also have an impact on the enlargement of the surface of the square, which will now be doubled from its surface, but also on vertical boundary surfaces, surrounding objects, axis traffic running parallel to it. These have a special importance in relation to the center-periphery relations, environmental factors, and in this case the nodes formed and which have been missing so far, and recently the formation of a new spatial sense of the city of Ferizaj.

While spatial syntax represents the characteristics of a given spatial unit - which are translated from a natural language into a graphic language, from a non-graphic document to a graphic document, from theory to practice. 